\title{
Energy expenditure and water turnover in hunting dogs in winter conditions
}

\author{
Øystein Ahlstrøm ${ }^{1 *}$, Paula Redman ${ }^{2}$ and John Speakman ${ }^{3}$ \\ ${ }^{1}$ Department of Animal and Aquacultural Sciences, Norwegian University of Life Sciences, PO Box 5003, N-1432 As, Norway \\ ${ }^{2}$ School of Biological Sciences, University of Aberdeen, Aberdeen, Scotland, UK \\ ${ }^{3}$ Institute of Biological and Environmental Sciences, University of Aberdeen, Aberdeen, Scotland, UK
}

(Received 21 October 2010 - Revised 26 January 2011 - Accepted 21 February 2011)

\section{Abstract}

Hunting with dogs in winter conditions is practised in the Nordic countries. The present study aimed at determining daily energy expenditure (DEE) and body water turnover (BWT) by the doubly labelled water technique in eight hunting dogs (body-weight (BW) range $14-27 \mathrm{~kg})$ working $3 \mathrm{~h} / \mathrm{d}$ for $3 \mathrm{~d}\left(-6^{\circ} \mathrm{C}\right)$ on ground covered with $20-40 \mathrm{~cm}$ of loose snow, to provide information on energy and water requirements. The mean distance run during the hunting period was recorded by the global positioning system and averaged $19.4 \mathrm{~km} / \mathrm{d}$. DEE increased with increasing BW $(P<0.001)$ and varied between 7.20 and $16.6 \mathrm{MJ} / \mathrm{d}$ (mean $11.0 \mathrm{MJ} / \mathrm{d}$ ) corresponding to $950-1350 \mathrm{~kJ} / \mathrm{kg} \mathrm{BW}^{075}$ per d (mean $1170 \mathrm{~kJ} / \mathrm{kg} \mathrm{BW}^{0.75}$ per d). The larger dogs tended to run longer than the smaller dogs and therefore spent more energy per kg BW ${ }^{0.75}$ but not significantly $(P>0.05)$. DEE values determined were close to the values measured for hunting dogs running for $3 \mathrm{~h} / \mathrm{d}$ in hot climates, suggesting that climate within the range of the two studies has little impact on energy expenditure per h running activity. Compared with the work of sled dogs per km travelled running on a track, the work performed by the hunting dogs was suggested to be higher when running in a loose snow layer. However, DEE was much lower because sled dogs ran for a longer distance each day. Mean BWT was $217 \mathrm{ml} / \mathrm{kg} \mathrm{BW}^{075}$ or $19 \mathrm{ml} / \mathrm{kJ}$ metabolisable energy.

\section{Key words: Hunting dog: Energy expenditure: Water turnover: Winter conditions}

Trained hunting dogs (gun dogs) display extraordinary working capacity by running several hours daily and covering long distances. The work that gun dogs do is to assist hunters in finding and retrieving different types of game, mainly birds. Bird hunting is particularly popular in Europe and the USA but also common in other parts of the world. It takes place in the autumn and winter period in various terrains and on different ground conditions, from open fields with solid ground to snow-covered mountain areas. Climate can vary from hot and humid to cold and dry with temperatures as low as $-20^{\circ} \mathrm{C}$. Endurance is the main quality required in a gun dog, and dog breeders and trainers show large interest in optimising the feeding of their dogs under various environmental conditions. Scientific information on the daily energy expenditure (DEE) and body water turnover (BWT) of dogs engaged in these activities, which is required for the correct supply of energy and water, is limited. The DEE and BWT have been measured in long-distance sled $\operatorname{dogs}{ }^{(1,2)}$, and this has some relevance for hunting dogs, but the daily work load in sled dogs is probably higher as they are pulling a weight and have a longer running period each day. In addition, unlike sled dogs, because of the nature of their work, hunting dogs also have periods of low activity mixed with high-intensity running. Moreover, ground conditions are very different between hunting and sled dogs, which may also affect the daily energy requirements.

A pilot study with two hunting dogs has shown that DEE was higher during hunting in winter conditions compared with controlled exercise, such as running on a treadmill or road running in harness, but results were not conclusive because of the low number of observations ${ }^{(3)}$. In the present study, we aimed to measure DEE and BWT by the doubly labelled water (DLW) technique in eight hunting dogs performing under rough winter conditions.

\section{Materials and methods \\ Dogs and location}

The experiment was conducted at the Department of Animal and Aquacultural Sciences, Norwegian University of Life Sciences, Norway. The use of live animals at the department was authorised by the Norwegian Animal Research Authority. The study comprised eight privately owned dogs (two Irish

Abbreviations: BW, body weight; BWT, body water turnover; DEE, daily energy expenditure; DLW, doubly labelled water; GPS, global positioning system; ME, metabolisable energy. 
setters, one English setter, two Gordon setters, two Brittany and one English pointer) with an average body weight (BW) of 19.8 (SD 3.8$) \mathrm{kg}$. The dogs were in good condition and healthy throughout the experiment. The body condition score, scale 1 (lean) to 5 (obese), was 2 for all dogs. The dogs were allowed to hunt with their owners for $3 \mathrm{~h} / \mathrm{d}$ for three consecutive days in a mountain habitat typical for ptarmigan (Lagopus lagopus) (altitude $1100 \mathrm{~m}$ ) located at Skinnarbu, Telemark, Norway $\left(59^{\circ} 87^{\prime} \mathrm{N}, 8^{\circ} 58^{\prime} \mathrm{E}\right)$. The terrain was a mix of small wooded hills and marshland. The maximum altitude difference was $150 \mathrm{~m}$ and hill climbing was moderate. The experiment was divided into two periods, one in late January and another in early February. Of the eight dogs, four were tested in each period. Climatic $\left(-6^{\circ} \mathrm{C}\right.$, light variable breeze, partly snowy weather) and ground conditions $(20-40 \mathrm{~cm}$ loose snow on top of a harder snow layer) were similar in the two periods. The start and end point of the hunting sessions was the same for every dog to balance up- and downhill running. When not hunting, the dogs were mainly resting and confined to $10 \mathrm{~m}^{2}$ (owner's room) at room temperature $\left(18-20^{\circ} \mathrm{C}\right)$.

\section{Recording of running distance}

The running distance covered was recorded by the global positioning system (GPS), type GEKO 201 (Garmin International, Inc., Olathe, KS, USA), weighing $85 \mathrm{~g}$ with a highest accuracy of $2 \mathrm{~m}$. The GPS receivers were placed in a small pocket on the dog's marker cloth. The pilot study ${ }^{(3)}$ has shown that identical receivers gave high accuracy for measurement of travelled distance of free running dogs. The receivers were checked regularly during the hunting period, and new batteries were provided after $2 \mathrm{~h}$ to avoid power shutdown.

\section{Measurement of energy expenditure and body water turnover}

A detailed description of the theoretical background and practical procedures for measuring DEE with the DLW technique has been given elsewhere ${ }^{(4)}$. We used a mix of highenrichment isotopes containing $33 \%$ of ${ }^{2} \mathrm{H}$ and $68 \%$ of ${ }^{18} \mathrm{O}$. Before subcutaneous injection of approximately $6 \mathrm{ml}$ $\left(10^{-4} \mathrm{~g}\right.$ accuracy) of DLW, a plasma sample was collected to determine the background isotope enrichment. After injection, the DLW was allowed to equilibrate for $5 \mathrm{~h}$ before collection of the initial sample. The hunting period started approximately $12 \mathrm{~h}$ after the initial sampling, and the final samplings were collected approximately $12 \mathrm{~h}$ after the $3 \mathrm{~d}$ hunting period. The total time period between the two samplings was $96 \mathrm{~h}$. To measure DEE in the hunting period, the isotope concentrations of the initial sample and the final sample were applied. Blood was sampled in $3 \mathrm{ml}$ vacutainers and centrifuged immediately. Then, three $100 \mu$ l glass capillaries were filled with plasma and heat-sealed with a gas torch using pending analysis. The isotope analyses (three replicates) were carried out as described by Speakman et al. ${ }^{(5)}$. Dilution spaces, $N_{\mathrm{d}}$ for ${ }^{2} \mathrm{H}$ and $N_{\mathrm{O}}$ for ${ }^{18} \mathrm{O}$, with respective elimination curves $\left(k_{\mathrm{d}}\right.$ and $\left.k_{\mathrm{o}}\right)$ for the isotopes were used to estimate $\mathrm{CO}_{2}$ production. The 'plateau' approach was applied for the determination of $N_{\mathrm{d}}$ and $N_{\mathrm{o}}$. The dry foods consumed by the dogs contained $22-25 \%$ protein, $20-25 \%$ fat and $35-40 \%$ carbohydrates. For these foods, a RQ of 0.85 was found suitable and therefore applied in the final step of the calculation of energy expenditure as described by Schoeller et $a l^{(6)}$. BW was recorded at the two blood samplings, and means were applied to calculate DEE and BWT.

BWT was calculated by the elimination curve for ${ }^{2} \mathrm{H}$ using the formula:

$$
k=\left(\ln C_{1}-\ln C_{2}\right) / \Delta t,
$$

where $k$ is the elimination rate for ${ }^{2} \mathrm{H}, C_{1}$ and $C_{2}$ are the initial and final ${ }^{2} \mathrm{H}$ enrichment in body water, respectively, and $\Delta t$ is the time between $C_{1}$ and $C_{2}$ sampling.

\section{Statistics}

The data presented are single values and means and standard deviations applying the PROC MEANS procedure of SAS ${ }^{(7)}$. Pearson's correlation coefficients (PROC CORR) and a simple regression model (PROC REG) were applied to test the relationship between $\mathrm{BW}$ and $\mathrm{km}$ travelled, and between BW and DEE, respectively. Relationships between BW and BWT data were tested by PROC REG.

\section{Results}

The isotope analyses revealed dilution space ratios $\left(N_{\mathrm{d}}: N_{\mathrm{O}}\right)$ between 1.03 and 1.08 and turnover ratios $\left(k_{\mathrm{o}}: k_{\mathrm{d}}\right)$ for ${ }^{18} \mathrm{O}$ and ${ }^{2} \mathrm{H}$ between 1.33 and 1.50 , both of which are in the acceptable range for calculating $\mathrm{CO}_{2}$ production. All dogs were injected with approximately the same volume $(6 \mathrm{ml})$ of DLW irrespective of BW. This volume worked well concerning measurements for all dogs, suggesting that the injection volume could have been reduced for smaller dogs without risking too low concentrations of isotopes at the final blood sampling.

The BW reduction after the hunting period was minor, 1.88 (SD $1 \cdot 1) \%$, and BW presented in Table 1 are means of the initial and final BW. The mean running distance for the eight dogs ranged from $15 \cdot 8$ to $24 \cdot 8 \mathrm{~km} / \mathrm{d}$ (Table 1 ). There was a slight tendency that the larger dogs ran longer than the smallest. The reason for this was probably that the smaller dogs had more problems with passing through areas of deep snow than the larger dogs. If the snow was deep, the dogs tended to hop instead of galloping, which they did if the top loose snow layer was thinner. The smallest dogs seemed to hop more frequently, because of their shorter legs, which may have slowed them down compared with the larger dogs with longer legs. However, there was no significant correlation between BW and $\mathrm{km}$ travelled ( $\left.r^{2} 0 \cdot 63 ; P<0 \cdot 12\right)$.

As expected, DEE increased with increasing BW (Table 1). The relationship between DEE and BW given by the regression equation, DEE $(\mathrm{MJ})=0.65 \times \mathrm{BW}(\mathrm{kg})-1.83$, was significant $(P<0 \cdot 001)$. The higher DEE with increasing BW was partly due to a higher maintenance requirement and 
Table 1. Body weights (BW), running distance, daily energy expenditure (DEE), body water (\%) and body water turnover (BWT) data in eight hunting dogs after hunting $3 \mathrm{~h} / \mathrm{d}$ for three consecutive days

(Mean values and standard deviations)

\begin{tabular}{|c|c|c|c|c|c|c|c|c|c|c|}
\hline & $\begin{array}{c}\text { Dog } 1 \\
\text { (Irish S, } \\
\text { male) }\end{array}$ & $\begin{array}{c}\text { Dog } 2 \\
\text { (English } \mathrm{P}, \\
\text { female) }\end{array}$ & $\begin{array}{c}\text { Dog } 3 \\
\text { (English S, } \\
\text { male) }\end{array}$ & $\begin{array}{l}\text { Dog } 4 \\
\text { (Irish S, } \\
\text { female) }\end{array}$ & $\begin{array}{c}\text { Dog } 5 \\
\text { (Gordon S, } \\
\text { female) }\end{array}$ & $\begin{array}{c}\text { Dog } 6 \\
\text { (Gordon S, } \\
\text { female) }\end{array}$ & $\begin{array}{c}\text { Dog } 7 \\
\text { (Brittany, } \\
\text { male) }\end{array}$ & $\begin{array}{c}\text { Dog } 8 \\
\text { (Brittany, } \\
\text { male) }\end{array}$ & Mean & SD \\
\hline BW (kg) & $27 \cdot 61$ & 23.90 & $22 \cdot 81$ & $19 \cdot 07$ & $18 \cdot 23$ & 17.46 & 14.80 & $14 \cdot 17$ & $19 \cdot 76$ & 4.7 \\
\hline Distance $(\mathrm{km} / \mathrm{d})$ & $19 \cdot 3$ & 23.0 & 24.8 & $17 \cdot 4$ & $18 \cdot 4$ & $19 \cdot 1$ & $15 \cdot 8$ & $17 \cdot 7$ & $19 \cdot 4$ & 3.0 \\
\hline DEE (MJ) & $16 \cdot 60$ & 13.50 & 12.57 & 10.37 & 9.29 & $10 \cdot 50$ & $7 \cdot 20$ & 7.93 & 11.00 & 3.1 \\
\hline $\mathrm{EE}\left(\mathrm{kJ} / \mathrm{kg} \mathrm{BW}^{0.75}\right)$ & 1350 & 1250 & 1210 & 1130 & 1140 & 1220 & 950 & 1080 & 1170 & 120 \\
\hline Body water (\%) & 68 & 67 & 64 & 63 & 66 & 67 & 62 & 61 & 65 & 2.6 \\
\hline BWT $(\mathrm{ml} / \mathrm{d})$ & 2590 & 2040 & 2740 & 1680 & 2050 & 1630 & 1840 & 1560 & 2015 & 440 \\
\hline BWT (ml/kg BW $\left.{ }^{0.75}\right)$ & 211 & 187 & 261 & 183 & 251 & 189 & 243 & 212 & 217 & 31 \\
\hline BWT $(\mathrm{ml} / \mathrm{kJ})$ & 0.16 & 0.15 & 0.22 & 0.16 & 0.22 & 0.15 & 0.26 & 0.20 & 0.19 & 0.04 \\
\hline
\end{tabular}

$\mathrm{EE}$, energy expenditure; $\mathrm{S}$, setter; $\mathrm{P}$, pointer.

partly because the energy need associated with movement increases with body size. It is interesting to note that by running a similar distance, the smallest dog (dog 8) spent about half of the energy compared with the largest (dog 1). However, the average DEE spent per $\mathrm{kg} \mathrm{BW}^{0.75}$ was rather similar for the two dogs, $1350 \mathrm{~kJ}$ metabolisable energy (ME) and $1080 \mathrm{~kJ} \mathrm{ME}$, respectively. Overall, the mean DEE was $11 \mathrm{MJ}$ corresponding to $1170 \mathrm{~kJ} / \mathrm{kg} \mathrm{BW}^{0.75}$ (Table 1).

BWT data, given in Table 1 , show that the mean BWT was $2015 \mathrm{ml} / \mathrm{d}$ and $217 \mathrm{ml} / \mathrm{kg} \mathrm{BW}^{0.75}$ corresponding to $0 \cdot 19 \mathrm{ml} / \mathrm{kJ}$. As expected, the values showed an increase in BWT $(\mathrm{ml} / \mathrm{d})$ with increasing BW. The relationship given by the regression equation BWT $(\mathrm{ml} / \mathrm{d})=548+74 \times \mathrm{BW}(\mathrm{kg})$ was significant $(P<0 \cdot 01)$. No such relationship $(P>0.05)$ was revealed between BW and BWT $\left(\mathrm{ml} / \mathrm{kg} \mathrm{BW}^{075}\right)$ or between BW and BWT $(\mathrm{ml} / \mathrm{kJ})$.

\section{Discussion}

The running distance covered by each dog was slightly longer than that measured by the GPS, as the GPS only measures horizontal movements. The terrain used for the experiment was not flat, and exact recordings including up- and downhill distance movements would probably have shown 3-4\% longer distance covered than that recorded by the GPS receivers.

The DEE determined in the present study is in line with a previous pilot study ${ }^{(1)}$, in which the dogs were exposed to similar climatic and ground conditions in one part of the study. However, our DEE values were slightly higher than the values reported by Davenport et al. ${ }^{(8)}$ based on ME consumption in English Pointers hunting for $3 \mathrm{~h} / \mathrm{d}(9.6 \mathrm{MJ} / \mathrm{d}$, $\left.1000 \mathrm{~kJ} / \mathrm{kg} \mathrm{BW}^{0.75}\right)$. In the latter study, environment and climate were very different from the present study, as the hunting area was fields and woodlands during hot and humid conditions in Georgia, USA. The impact of increased energy requirement due to heat stress during hunting and rest was probably lower in the present study than in the study of Davenport et al. ${ }^{(8)}$, where the dogs were exposed to high ambient temperature and air moisture. Moreover, the distance covered by the dogs was not recorded in the latter study, and it is therefore difficult to compare the workload of running in the two experiments. However, the similarity of DEE values in the two studies, despite differences in environmental and ground conditions, suggests that trained hunting dogs willing to work with the same intensity will spend about the same amount of energy per h of hunting irrespective of climate and terrain.

Reports on DEE measurements in sled dogs have shown considerably higher levels compared with those measured for the dogs in the present study ${ }^{(1,2)}$. This is mainly because running time per day has been longer for the sled dogs. Hinchcliff et al. ${ }^{(1)}$ examined DEE in sled dogs $(490 \mathrm{~km}$ in $70 \mathrm{~h}$ ) and found that they spent an impressive $44.6 \mathrm{MJ}$ corresponding to $4400 \mathrm{~kJ} / \mathrm{kg} \mathrm{BW}^{0.75}$. In another study ${ }^{(2)}$ with Inuit sled dogs running $60-80 \mathrm{~km} / \mathrm{d}$ on sea ice, DEE was measured to be $25.7 \mathrm{MJ}$ or $2150 \mathrm{~kJ} / \mathrm{kg} \mathrm{BW} \mathrm{BW}^{0.75}$. The maintenance energy requirement in the first study was determined to be $550 \mathrm{~kJ} /$ $\mathrm{kg} \mathrm{BW}{ }^{0.75}$ per $\mathrm{d}$, corresponding to $3850 \mathrm{~kJ} / \mathrm{kg} \mathrm{BW}{ }^{0.75}$ for muscle work. The dogs ran $168 \mathrm{~km} / \mathrm{d}$, which represented an energy cost of $22.9 \mathrm{~kJ} / \mathrm{kg} \mathrm{BW}{ }^{075}$ per $\mathrm{km}$. If a similar maintenance energy requirement is applied for the dogs in the present study, the total DEE would amount to $2 \cdot 1$ times the maintenance energy requirement and the energy spent per $\mathrm{km}$ travelled would be $32.0 \mathrm{~kJ} / \mathrm{kg} \mathrm{BW}^{0.75}$. The dogs in the present study ran at $6.5 \mathrm{~km} / \mathrm{h}$, while the sled dogs ran $7 \mathrm{~km} / \mathrm{h}$. Even though this type of comparisons should be interpreted with some caution since maintenance energy requirements were not determined in the present study, it may be suggested that running in loose snow as our dogs did is more energy consuming per $\mathrm{km}$ than running at the same speed pulling a sledge on a track.

Water supply comes from drinking-water, water in food and water produced from oxidation of the main nutrients (metabolic water), and water losses are represented by water in urine, faeces and evaporated water in respired air. Factors that influence water intake are food intake, dietary salt, ambient temperature and exercise level. Water requirement normally increases parallel to energy expenditure, and a rule of thumb is that the water requirement is $0.24 \mathrm{ml} / \mathrm{kJ}$ $\mathrm{ME}^{(9)}$. The low BWT indicates that the dogs were little affected by heat stress during hunting, and that the water requirement was lower than that in inactive dogs when measured in relation to energy expenditure. 


\section{Conclusions}

The present study revealed that DEE in hunting dogs was $1170 \mathrm{~kJ} / \mathrm{kg} \mathrm{BW} \mathrm{BW}^{0.75}$ when working for $3 \mathrm{~h} / \mathrm{d}$ in winter conditions $\left(-6^{\circ} \mathrm{C}\right)$ with a $20-40 \mathrm{~cm}$ loose snow layer. BWT was $217 \mathrm{ml} / \mathrm{kg} \mathrm{BW}^{0.75}$ or $19 \mathrm{ml} / \mathrm{kJ} \mathrm{ME}$.

\section{Acknowledgements}

We would like to thank Telemark Fuglehundklubb for allowing us to use their hunting grounds. We acknowledge the dog owners taking part in the study: Siri Kulberg Sjurseth, Finn Holm Nygaard, Per Holm Nygaard, Roy Andersen, Lars Arnesen, Nina Hagesæther, Even Bergseng and Bente Wejden. The study was funded by the Department of Animal and Aquacultural Sciences, Norwegian University of Life Sciences. There are no conflicts of interest. The contribution of each author was as follows: $\varnothing$. A. conducted the study and wrote the manuscript. P. R. and J. S. carried out the analyses and calculations concerning DLW.

\section{References}

1. Hinchcliff KW, Reinhart GA, Burr JR, et al. (1997) Metabolizable energy intake and sustained energy expenditure of Alaskan sled dogs during heavy exertion in the cold. $A m J$ Vet Res 58, 1457-1462.

2. Gerth N, Redman P, Speakman J, et al. (2010) Energy metabolism of Inuit sled dogs. J Comp Physiol B 180, 577-589.

3. Ahlstrøm $\varnothing$, Skrede A, Speakman J, et al. (2005) Energy expenditure and water turnover in hunting dogs: a pilot study. J Nutr 136, 2063S-2065S.

4. Speakman J (1997) Doubly Labelled Water. Theory and Practice. London: Chapman and Hall.

5. Speakman JR, Perez-Camargo G, McCappin T, et al. (2001) Validation of the doubly labeled water technique in the domestic dog (Canis familiaris). Br J Nutr 85, 75-87.

6. Schoeller DA, Raussin E \& Schutz Y (1986) Energy expenditure by doubly-labelled water validation in humans and proposed calculations. Am J Physiol 250, R23-R30.

7. SAS, 2004. Version 9.1 TS. Cary, NC: SAS Institute, Inc.

8. Davenport GM, Kelley RL, Altom EK, et al. (2001) Effect of diet on hunting performance of English Pointers. Vet Ther 2, 10-23.

9. National Research Council (2006) Nutrient Requirements of Dogs and Cats. Washington, DC: National Academies Press.

1

